\title{
Descriptive study of clinical profile and benefit of therapy in childhood hypercalciuria
}

This article was published in the following Dove Press journal: International Journal of Nephrology and Renovascular Disease 7 February 2014

Number of times this article has been viewed

\section{Mahalingam Vijayakumar \\ Prahlad Nageswaran \\ O Manimegalai Tirukalathi \\ Ekambaram Sudha \\ Shweta Priyadarshini}

Department of Pediatric Nephrology and Pediatrics, Mehta Children's

Hospital, Chennai, Tamilnadu, India
Correspondence: Mahalingam

Vijayakumar

Mehta Children's Hospital,

2E McNichols Road, Third Lane,

Chetpet, Chennai 600 03I,

Tamilnadu, India

Email doctormvk@gmail.com

\begin{abstract}
Clinical, biochemical, and ultrasonographic findings in 91 consecutive children presenting with hypercalciuria were analyzed along with the results of treatment to determine the clinical profile of hypercalciuria and its outcome. Hypercalciuria was common in children aged $1-5$ years $(39.6 \%)$, and hematuria was the most frequent symptom. There was no significant difference between 24-hour urinary calcium and random urinary calcium/creatinine ratio values between males and females. The random urinary calcium/creatinine ratio was found to be useful for screening and also for documenting the benefit of therapy. The children were essentially treated with thiazides, and the majority showed a good response, with a good overall outcome on follow-up.
\end{abstract}

Keywords: hematuria, hypercalciuria, thiazides

\section{Introduction}

Hypercalciuria is an increasingly recognized cause of inherited metabolic tubular disorders in children and is also one of the commonest causes of hematuria. ${ }^{1}$ Hypercalciuria in children can lead to tubulointerstitial damage resulting in chronic kidney disease. We studied the clinical profile and benefit of therapy for children with hypercalciuria from a southern region in India.

\section{Materials and methods}

This descriptive study included 91 consecutive children presenting to the pediatric nephrology clinic of a tertiary pediatric hospital with various urinary symptoms, recurrent abdominal pain, or renal stones, in whom hypercalciuria was documented on evaluation. The children were included in this study after clearance from our ethics committee. The study aims were to document the presenting symptoms, clinical signs, biochemical and sonographic findings, and family clustering patterns in these cases, and to classify them as idiopathic or secondary hypercalciuria. The children were followed up for 12 months and the benefit of therapy was documented.

Hypercalciuria was defined as a 24-hour urinary calcium excretion $>4 \mathrm{mg} / \mathrm{kg} /$ day or two of three random urinary calcium/creatinine $(\mathrm{Ca} / \mathrm{Cr})$ ratios $>0.21$ after one year of age or $>0.8$ in infants for whom 24-hour urine collection was not feasible. The presenting symptoms and clinical signs formed the clinical profile. Basic biochemical and ultrasonographic evaluations were done. Family clustering was done in hypercalciuric children with a family history of renal stone disease or hypercalciuria. The profile of family members with a positive history was investigated to document hypercalciuria. 
All children had a 24-hour urinary calcium excretion or random urine $\mathrm{Ca} / \mathrm{Cr}$ ratio done on three occasions. Urinary creatinine was estimated using the Jaffe kinetic reaction. Twenty-four-hour urinary calcium and spot urine were analyzed using an automatic analyzer (Selectra-E, Vital Scientific NV, Dieren, the Netherlands). Hydrochloric acid was used as a preservative in the 24-hour urine collections. Blood sugar and urea, serum creatinine, electrolytes, uric acid, calcium, phosphorus, alkaline phosphatase, and albumin measurements, urinalysis, and ultrasonography of the abdomen were done at the beginning of the study.

Blood tests and ultrasonography were repeated once in 3-6 months to monitor the side effects and benefits of thiazide therapy. A serum lipid profile was done once in 6 months or earlier if blood sugar was elevated. If suspected, the possibility of renal tubular acidosis was evaluated with further investigations, including arterial blood gas, urine $\mathrm{pH}$, and urinary anion gap testing. Serum vitamin D and parathyroid hormone levels were measured depending on the clinical situation.

The children were followed up once in 3 months. Children with idiopathic hypercalciuria were advised to increase their water intake to 1-3 L per day depending on their age, restrict their salt intake to $2-3 \mathrm{~g}$ per day according to age, and were prescribed oral hydrochlorothiazide $1 \mathrm{mg} / \mathrm{kg} /$ day. In children with secondary causes, appropriate specific treatment was given.

The above management was continued in all children during the study period. At the end of one year, the benefit of therapy was assessed and documented by symptom analysis and by doing spot urine calcium creatinine ratio.
Statistical analysis was performed using Statistical Package for the Social Sciences version 11.5 software (IBM Corporation, Armonk, NY, USA). Demographic data are shown as frequencies with their percentages. Biochemical data are given as the mean and standard deviation. Agespecific sex distributions were analyzed using the chi-square test. Random urinary $\mathrm{Ca} / \mathrm{Cr}$ ratio and 24-hour urinary calcium values were compared between males and females using the Student's independent $t$-test.

\section{Results}

Of the 91 hypercalciuric children enrolled in this study, $52(57.14 \%)$ were males and $39(42.86 \%)$ were females, with an overall mean age of $6.51 \pm 4.3$ years. The youngest was aged 39 days and the oldest was 17 years. There was a significant difference seen according to age group ( $P=0.001$ ), with hypercalciuria most commonly diagnosed in patients aged $1-5$ years (Figure 1). Interestingly, there was a male preponderance in all age groups, except in patients aged $1-5$ years, in which there was a female preponderance (Figure 1), which was statistically significant $(P=0.01)$.

The various common presenting symptoms are shown in Table 1. Hematuria was the commonest presentation, and urinary tract infection was documented in 21 cases. Of the 91 children, 37 had a positive family history of either stone disease or hypercalciuria. Secondary hypercalciuria was documented in eleven children, of whom nine had distal renal tubular acidosis and two had hypomagnesemia and hypocalcemia with hypercalciuria.

Analysis of random urine $\mathrm{Ca} / \mathrm{Cr}$ ratio and 24-hour urinary calcium yielded mean measurements of $0.65 \pm 0.21$

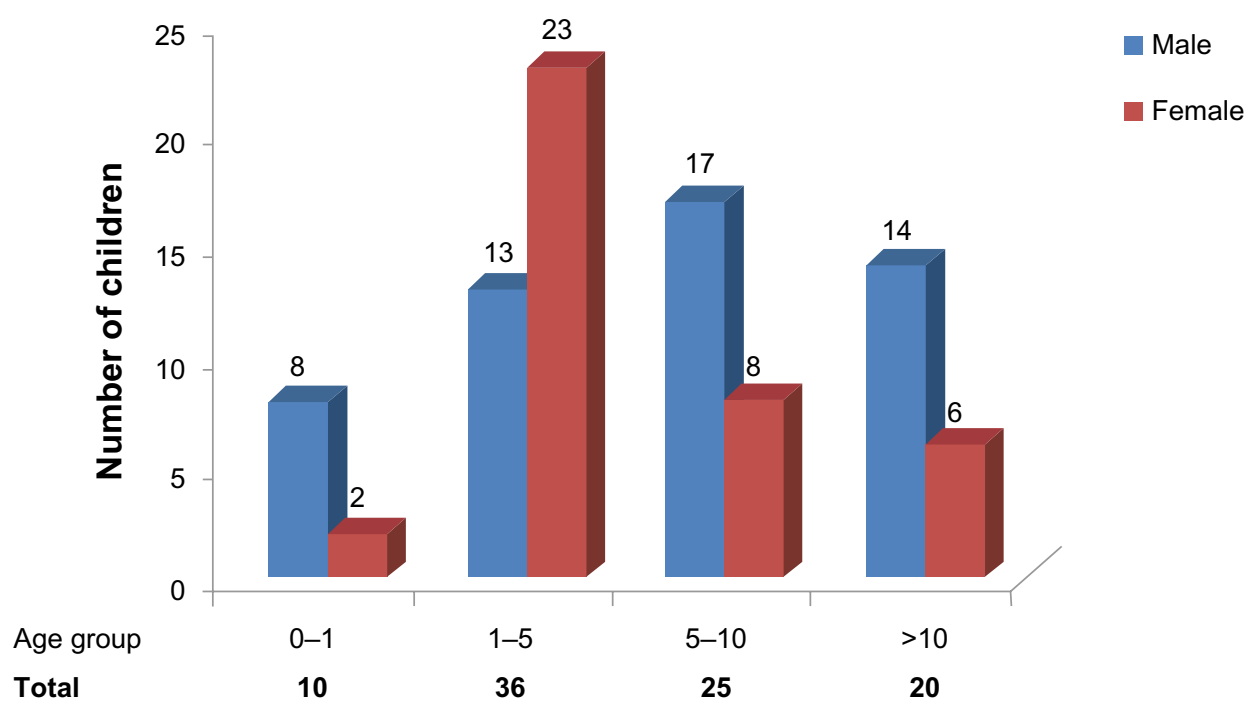

Figure I Age-specific sex distribution ( $\mathrm{n}=91)$. 
Table I Age-wise distribution of symptoms ( $n=91)$

\begin{tabular}{|c|c|c|c|c|c|c|}
\hline Age group & Hematuria & Enuresis & Frequency & Passage of stones & Dysuria & Abdominal pain \\
\hline $1-12$ months & 1 & - & 9 & I & - & - \\
\hline I-5 years & 12 & - & 15 & 3 & 14 & 6 \\
\hline $5-10$ years & 13 & 10 & 11 & 2 & 9 & 11 \\
\hline$>10$ years & 16 & 2 & 6 & 3 & 11 & 12 \\
\hline Total & 42 & 12 & 36 & 9 & 34 & 29 \\
\hline
\end{tabular}

and $6.42 \pm 2.92$, respectively. When these two parameters were compared between males and females, there was no statistically significant difference $(P=0.15$ and $P=0.98$, respectively).

Serum electrolytes (sodium, potassium, chloride, bicarbonate) were measured in all the children as part of their initial evaluation. Nine had distal renal tubular acidosis and accordingly had hypokalemia, hyperchloremia, and metabolic acidosis. All children with idiopathic hypercalciuria had normal serum electrolytes.

Serum parathyroid hormone levels were normal in all the children with distal renal tubular acidosis. One patient with hypercalciuria had stage 2 chronic kidney disease and his parathyroid hormone level was found to be elevated. One of two children with familial hypocalcemia and hypomagnesemia with hypercalciuria had a parathyroid hormone level slightly on the higher side and the second child had a normal level.

Sixteen children had renal stones on ultrasonography. Of these, nine had a history of passing stones; of the remaining seven children, three had microlithiasis, three had medullary nephrocalcinosis, and one had a $5 \mathrm{~mm}$ calculus in the right upper calyx.

Of the 91 children initially included in the study, 18 were lost to follow-up. All 73 children who remained under follow-up improved symptomatically, with 26 showing regression of symptoms along with either normalization or reduction of their urine $\mathrm{Ca} / \mathrm{Cr}$ ratio. Analysis of random urine $\mathrm{Ca} / \mathrm{Cr}$ at the end of one year in these 26 cases showed a mean value of $0.14 \pm 0.05$, with a mean of $0.31 \pm 0.09$ recorded in the remaining 47 children. In all the age groups, there was a reduction in the spot urine $\mathrm{Ca} / \mathrm{Cr}$ ratio from baseline following therapy, that was statistically significant in all age groups (Table 2 and Figure 2). In children with renal tubular acidosis, hypercalciuria improved on treatment with alkalinizing agents whereas in children with hypomagnesemia and hypocalcemia with hypercalciuria, the hypercalciuria was seen to persist at the end of one year.

No children on treatment developed new stones or elevated renal parameters during the study. When followed up for complications of drug therapy, two children had hypercalcemia and one child developed hyperglycemia (without hypertriglyceridemia) that resolved after temporary cessation of hydrochlorothiazide. Subsequently these children were given the lowest possible drug dose and derived benefit from treatment, with no further hypercalcemic or hyperglycemic episodes.

\section{Discussion}

Hypercalciuria is the most common metabolic abnormality found in children with renal stones. Hypercalciuria is considered to be idiopathic if the serum calcium level is normal and known causes of normocalcemic hypercalciuria have been excluded. ${ }^{2}$ There is a wide variation in the prevalence of idiopathic hypercalciuria between countries. The prevalence of hypercalciuria in India according to an earlier study by Rath et al was reported to $6.5 \%,{ }^{3}$ and we identified 91 children with hypercalciuria over a period of 5 years.

Studies reported by Esfahani et al, Rath et al, and Polito et al show a male preponderance of idiopathic hypercalciuria, which was again found in our study. ${ }^{1,3,4}$ However, according to a study done by Safaei et al in Rasht, Iran, the prevalence of idiopathic hypercalciuria in males and females was the same. $^{5}$

Kalia et al reported a 10-week-old infant with hypercalciuria, ${ }^{6}$ whereas the youngest baby in our study was 39 days old. In the literature, the peak incidence of hypercalciuria documented in children is in the age group of 4-8 years, ${ }^{7}$ and in our study most cases were aged $1-5$ years.

Macroscopic hematuria was the commonest symptom (46.2\%), as in previous studies, ${ }^{6,8}$ being the major noncalculi

Table 2 Spot urine calcium/creatinine ratio before and after therapy

\begin{tabular}{llll}
\hline Age group & Pre therapy & Post therapy & Paired $t$-test \\
\hline $0-12$ months & $0.88 \pm 0.45$ & $0.32 \pm 0.26$ & $t=3.89, P=0.01$ \\
$1-5$ years & $0.64 \pm 0.77$ & $0.28 \pm 0.18$ & $t=3.33, P=0.01$ \\
$5-10$ years & $0.26 \pm 0.29$ & $0.20 \pm 0.12$ & $t=2.16, P=0.02$ \\
$>10$ years & $0.65 \pm 0.65$ & $0.23 \pm 0.14$ & $t=3.21, P=0.01$ \\
Overall & $0.55 \pm 0.63$ & $0.24 \pm 0.22$ & $t=5.40, P=0.001$ \\
\hline
\end{tabular}




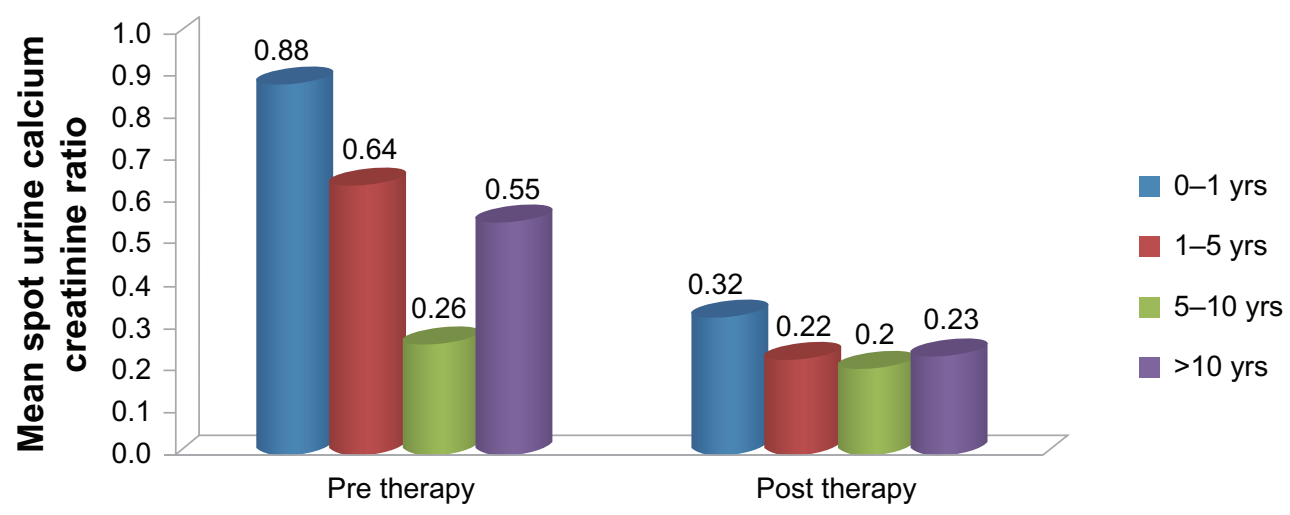

Figure 2 Spot urinary calcium/creatinine ratio before and after therapy.

manifestation of idiopathic hypercalciuria in children. ${ }^{8}$ Idiopathic hypercalciuria may have a significant role in children with vague symptoms like enuresis and dysuria and in those with abdominal symptoms. Some children can have crystalluria or pass gravel in their urine. Both Lopez et al and Stojanovic et al concluded that idiopathic hypercalciuria is a factor contributing to urinary tract infection. ${ }^{79}$ A study done by Nacaroglu et al concluded that idiopathic hypercalciuria should be considered among the risk factors for urinary tract infection and should be investigated particularly in patients with a family history of renal stones and complaints suggestive of idiopathic hypercalciuria. ${ }^{10}$ In our study, we documented recurrent urinary tract infection in 21 children.

In a study done by Safaei et al, a family history of urinary calculi in first-degree relatives was found in $63.2 \%$ of patients with hypercalciuria. ${ }^{5}$ In our study, 37 of 91 children had a positive family history of either stone disease or hypercalciuria, indicating that idiopathic hypercalciuria may be a complex condition resulting from inheritance in association with various risk factors like diet, environment, high salt intake, and reduced fluid intake. Perusal of the medical records for family members of the 37 children with a positive family history showed that 20 had a history of stone disease in their parents or siblings, 14 had stone disease in either maternal or paternal, aunts or uncles, and four children had one parent with hypercalciuria without documented stone disease but with history of hematuria. Apart from these four parents, the remaining 33 were evaluated for hypercalciuria and eight of them had normocalcemic hypercalciuria of $>4 \mathrm{mg} / \mathrm{kg} /$ day and were being treated by adult physicians. This finding stresses the importance of studies to unravel genes and to determine their role in the pathogenesis of hypercalciuria.

In a review of various studies, Butani et al opined that urinary calcium excretion varies between different populations, age groups, and ethnic groups. Although a 24-hour urine collection is preferred for quantifying calcium excretion, the urine $\mathrm{Ca} / \mathrm{Cr}$ ratio is much easier to obtain and correlates with the 24-hour data, but random urine samples are affected by factors such as dietary calcium intake. ${ }^{11}$ In very young children, many investigators have used the urinary $\mathrm{Ca} / \mathrm{Cr}$ ratio as an alternative measurement. ${ }^{3}$ In the present study, we used the random urine $\mathrm{Ca} / \mathrm{Cr}$ ratio as a screening test and 24-hour urinary calcium as the definitive tool for diagnosing hypercalciuria. In younger infants less than 7 months of age who are predominantly on a milk diet, hypercalciuria can be considered when the random urine $\mathrm{Ca} / \mathrm{Cr}$ ratio is $>0.8 .{ }^{12}$ Ultrasonography of the abdomen can be performed to document renal stone disease. Polito et al reported 42 children with microcalculi and four with calculi on ultrasonography ${ }^{1}$ and we identified 16 children with renal stones in this way.

\section{Conclusion}

Hypercalciuria is a lifelong metabolic disease, and with proper treatment the associated morbidity can be reduced by alleviating symptoms and the impact of its secondary effects of uroepithelial damage.

\section{Acknowledgment}

We are grateful to A Vengatesan in the Department of Statistics at Madras Medical College for his kind help with the statistical analysis.

\section{Author contributions}

All authors contributed toward data analysis, drafting and revising the manuscript.

\section{Disclosure}

The authors report no conflicts of interest in this work. 


\section{References}

1. Polito C, La Manna A, Cioce F, Villani J, Nappi B, Di Toro R. Clinical presentation and natural course of idiopathic hypercalciuria in children. Pediatr Nephrol. 2000;15:211-214.

2. Vijayakumar M. Medical nephrolithiasis. In: Nammalwar BR, Vijayakumar M, editors. Principles and Practice of Pediatric Nephrology. 1st ed. New Delhi, India: Jaypee Brothers; 2004.

3. Rath B, Aggarwal MK, Mishra TK, Talukdar B, Murthy NS, Kabi BC. Urinary calcium creatinine ratio and hypercalciuria. Indian Pediatr. 1994;31:311-316.

4. Esfahani ST, Madani A, Siadati AA, Nabavi M. Prevalence and symptoms of idiopathic hypercalciuria in primary school children of Tehran. Iran J Pediatr. 2007;17:353-358.

5. Safaei AA, Heidarzadeh A, Maleknejad S. Hypercalciuria in schoolaged children of Rasht: a single-center study. Iran J Kidney Dis. 2013;7: 265-267.

6. Kalia A, Travis LB, Brouhard BH. The association of idiopathic hypercalciuria and asymptomatic gross hematuria in children. J Pediatr. 1981;99: 716-719.
7. Stojanovic VD, Milosevic BO, Djapic MB, Bubalo JD. Idiopathic hypercalciuria associated with urinary tract infection in children. Pediatr Nephrol. 2007;22:1291-1295.

8. Stapleton FB, Roy S 3rd, Noe HN, Jerkins G. Hypercalciuria in children with hematuria. N Engl J Med. 1984;310:1345-1348.

9. Lopez MM, Castillo LA, Chavez B, Ramones C. Hypercalciuria and recurrent urinary tract infection in Venezuelan children. Pediatr Nephrol. 1999;13:433-437.

10. Nacaroglu HT, Demircin G, Bülbül M, Erdogan O, Akyüz SG, CaltikA. The association between urinary tract infection and idiopathic hypercalciuria in children. Ren Fail. 2013;35:327-332.

11. Butani L, Kalia A. Idiopathic hypercalciuria in children - how valid are the existing diagnostic criteria. Pediatr Nephrol. 2004;19:577-582.

12. Sargent JD, Stukel TA, Kresel J, Klein RZ. Normal values for random urinary calcium to creatinine ratios in infancy. $J$ Pediatr. $1993 ; 123: 393-397$.

\section{Publish your work in this journal}

The International Journal of Nephrology and Renovascular Disease is an international, peer-reviewed open-access journal focusing on the pathophysiology of the kidney and vascular supply. Epidemiology, screening, diagnosis, and treatment interventions are covered as well as basic science, biochemical and immunological studies. The journal welcomes original research, clinical studies, reviews \& evaluations, expert opinion and commentary, case reports and extended reports. The manuscript management system is completely online and includes a very quick and fair peerreview system, which is all easy to use. Visit http://www.dovepress.com/ testimonials.php to read real quotes from published authors.

Submit your manuscript here: http://www.dovepress.com/international-journal-of-nephrology-and-renovascular-disease-journal 